\title{
src homology 2 domain-containing tyrosine phosphatase SHP-1 controls the development of allergic airway inflammation
}

\author{
Tohru Kamata, ${ }^{1}$ Masakatsu Yamashita, ${ }^{1,2}$ Motoko Kimura, ${ }^{1}$ Kaoru Murata, ${ }^{1}$ \\ Masamichi Inami, ${ }^{1}$ Chiori Shimizu, ${ }^{1}$ Kaoru Sugaya, ${ }^{2}$ Chrong-Reen Wang, ${ }^{3}$ \\ Masaru Taniguchi, ${ }^{1,4}$ and Toshinori Nakayama ${ }^{1,5}$
}

\begin{abstract}
${ }^{1}$ Department of Molecular Immunology, Graduate School of Medicine, Chiba University, Chiba, Japan ${ }^{2}$ PRESTO Project, Japan Science and Technology Corporation, Tokyo, Japan

${ }^{3}$ Section of Allergy, Immunology and Rheumatology, Department of Internal Medicine, Medical College, National Cheng Kung University, Tainan, Taiwan

${ }^{4}$ Laboratory for Immune Regulation, RIKEN Research Center for Allergy and Immunology, Yokohama, Japan

${ }^{5}$ Department of Medical Immunology, Graduate School of Medicine, Chiba University, Chiba, Japan
\end{abstract}

Th2 cells are generated from naive CD4 $\mathrm{T}$ cells upon $\mathrm{T}$ cell receptor (TCR) recognition of antigen and IL-4 stimulation and play crucial roles in humoral immunity against infectious microorganisms and the pathogenesis of allergic and autoimmune diseases. A tyrosine phosphatase, SHP-1, that contains $s r c$ homology 2 (SH2) domains is recognized as a negative regulator for various intracellular signaling molecules, including those downstream of the TCR and the IL-4 receptor. Here we assessed the role of SHP-1 in Th1/Th2 cell differentiation and in the development of Th2-dependent allergic airway inflammation by using a natural SHP-1 mutant, the motheaten mouse. CD4 T cells appear to develop normally in the heterozygous motheaten $(m e /+)$ thymus even though they express decreased amounts of SHP-1 (about one-third the level of wild-type thymus). The me/+ naive splenic CD4 T cells showed enhanced activation by IL-4 receptor-mediated signaling but only marginal enhancement of TCR-mediated signaling. Interestingly, the generation of Th2 cells was increased and specific cytokine production of mast cells was enhanced in me/+ mice. In an OVA-induced allergic airway inflammation model, eosinophilic inflammation, mucus hyperproduction, and airway hyperresponsiveness were enhanced in $m e /+$ mice. Thus, SHP-1 may have a role as a negative regulator in the development of allergic responses, such as allergic asthma.

J. Clin. Invest. 111:109-119 (2003). doi:10.1172/JCI200315719.

\section{Introduction}

$\mathrm{CD}^{+}$Th cells are divided into two distinct subpopulations on the basis of their cytokine production profiles (1). Th2 cells produce IL-4, IL-5, and IL-13, whereas Th1 cells produce IFN- $\gamma$ and TNF- $\beta(2-5)$. Since these cytokines exert distinct biological functions in various immune responses, the investigation of the

Received for publication April 17, 2002, and accepted in revised form November 12, 2002.

Address correspondence to: Toshinori Nakayama, Department of Medical Immunology, Graduate School of Medicine, Chiba University, 1-8-1 Inohana, Chuo-ku, Chiba 260-8670, Japan. Phone: 81-43-226-2200; Fax: 81-43-227-1498;

E-mail: nakayama@med.m.chiba-u.ac.jp.

Tohru Kamata and Masakatsu Yamashita contributed equally to this work.

Conflict of interest: The authors have declared that no conflict of interest exists.

Nonstandard abbreviations used: IL-4 receptor (IL-4R); T cell receptor (TCR); src homology 2 (SH2); protein tyrosine kinase (PTK); transgenic (Tg); bronchoalveolar lavage (BAL);

phycoerythrin (PE); bone marrow-derived mast cell (BMMC); dinitrophenyl (DNP); aluminum hydroxide gel (alum); periodic acid-Schiff (PAS); protein tyrosine phosphatase (PTP); myelin basic protein (MBP); experimental autoimmune encephalomyelitis (EAE). molecular mechanisms governing Th1/Th2 cell development is essential for understanding immune responses toward infectious diseases and the pathogenesis of allergic and autoimmune diseases. For successful Th2 cell development, naive $\mathrm{CD} 4 \mathrm{~T}$ cells require IL-4 receptor-mediated (IL-4R-mediated) STAT6 activation (6-8) and efficient $\mathrm{T}$ cell receptor-mediated (TCR-mediated) activation of calcineurin and the Ras-ERK MAPK cascade $(9,10)$. However, the role for negative regulators of intracellular signaling in Th1/Th2 cell development is not well understood.

A cytoplasmic protein that contains src homology 2 (SH2) domains, the tyrosine phosphatase SHP-1, is expressed predominantly in hematopoietic cells (11) and is known to be one of the negative regulators of cell signaling $(12,13)$. The SHP-1 molecule consists of two N-terminal-located SH2 domains, a single phosphatase domain, and a C-terminal tail encompassing two sites for tyrosine phosphorylation (14). Biochemical and structural characterization of SHP-1 has revealed its catalytic function to be regulated by structural rearrangement of the $\mathrm{SH} 2$ domains $(15,16)$. Our understanding of the biological function of SHP-1 has been dramatically enhanced by the discovery of two 
loss-of-function mutant mice. Profound immunological dysfunction was observed in mice homozygous for the motheaten mutation $(\mathrm{me} / \mathrm{me})$ or the viable motheaten mutation $\left(m e^{v} / m e^{v}\right)(17,18)$. It was shown that SHP-1 phosphatase counterbalances protein tyrosine kinase activation in lymphocytes and modulates the magnitude and kinetics of signaling downstream of the antigen receptor, thus determining the biological outcome of antigen receptor engagement (12). SHP-1 has been reported to regulate $B$ cell receptor-induced proliferative responses and apoptosis (19-21). Negative regulation by CD22 in $\mathrm{B}$ cell receptor signaling appears to be associated with physically associated SHP-1 molecules $(22,23)$. In NK cells, the mechanisms whereby SHP-1 inhibits NK cytotoxicity are not fully understood, although recent data suggest that the killer cell inhibitory receptor recruits SHP-1 and suppresses the earliest activation signaling events induced by FcR engagement (24-26).

The hyperreactivity of $\mathrm{T}$ cells in $m e / m e$ mice was first described in $1996(27,28)$. SHP-1 was shown to downregulate the TCR-induced activation of $s r c$-family protein tyrosine kinases (PTKs), such as Lck and Fyn (28), and to associate with and dephosphorylate ZAP-70 kinase (29). Then, SHP-1 was found to modify various biological outcomes of TCR engagement, including TCR-specific thymocyte selection and apoptosis (30-33). For example, an analysis of H-Y TCR transgenic $(\mathrm{Tg})$ mice with the SHP-1 mev mutation revealed that TCR-induced proliferation, thymocyte maturation, and clonal deletion are enhanced in these mice (30). These results suggest that SHP-1 regulates the strength of TCR-mediated signals by modifying PTK activation (33). In addition, SHP-1 appears to control signal transduction downstream of various cytokine receptors, including erythropoietin receptor (34), IFN- $\alpha \beta$ receptor (35), IL-2R (36), IL-3R (37), and IL-4R and IL-13R (38), probably through the inactivation of Jak kinases by dephosphorylation.

The clinical and biological manifestations of bronchial asthma are heterogeneous, reflecting the presence of complex pathophysiological mechanisms. Among them, airway inflammation is a central issue in the pathogenesis of asthma. Chronic inflammation characterized by leukocyte infiltration in the peribronchiolar and perivascular regions of the lung, hypersecretion of mucus, obstruction of airways, epithelial damage, and basement membrane thickening are observed in asthmatic lung tissue (39). It has been revealed that $\mathrm{CD}^{+} \mathrm{Th} 2$ cells and eosinophils play crucial roles in allergic airway inflammation and allergeninduced airway hyperresponsiveness (40-42). Th2 cytokines, including IL-4, IL-5, and IL-13, are critical for the development of the asthma phenotype (43-47). More recently, the role for intracellular signaling molecules in the pathogenesis of allergic asthma was investigated in gene-manipulated animals and in experimental OVA-induced allergic airway inflammation models. STAT6 has been reported to be critical for the development of antigen-induced airway hyperresponsiveness and mucus production (48). Mice deficient in the p50 subunit of NF- $\mathrm{KB}$, which lack IL-5 and eotaxin production, show a decrease in the number of eosinophils in allergic airway inflammation (49). The inhibition of GATA3 activity in dominant negative GATA3 Tg mice results in a reduction in Th2 cytokine production and less severe allergic inflammation in a murine model of asthma (50). Moreover, allergic airway inflammation and hyperresponsiveness have been reported to be compromised by the intranasal administration of antisense GATA3 (51).

Here, we investigated the role of SHP- 1 in Th1/Th2 cell differentiation and allergic airway inflammation using heterozygous motheaten $(m e /+)$ mice, whose CD4 T cells appear to develop normally even though SHP-1 expression is lower than in wild-type mice (about one-third). Naive splenic CD4 T cells from me/+ mice showed significantly enhanced IL-4R signaling and increased Th2 cell differentiation. In an OVAinduced allergic airway inflammation model, peribronchial and perivascular inflammation, eosinophilic infiltrations in bronchoalveolar lavage (BAL) fluid, and airway hyperresponsiveness were enhanced in $\mathrm{me} /+$ mice. Thus, SHP-1 appears to play a key role as a negative regulator in the generation of asthma phenotype.

\section{Methods}

Animals. Mice heterozygous for the motheaten mutation $(m e /+)$ with $\mathrm{C} 3 \mathrm{HeB} / \mathrm{Fej}-\mathrm{a} / \mathrm{a}$ background were kindly provided by Hajime Takayama (Mitsubishi Kasai Institute of Life Science, Tokyo, Japan). All mice were maintained under specific pathogen-free conditions and were used at 6-8 weeks of age. Genotyping was done with PCR amplification of tail DNA as described previously (18). Animal care was in accordance with the guidelines of Chiba University.

Immunofluorescent staining and flow cytometry analysis. In general, 1 million cells were incubated on ice for $30 \mathrm{~min}$ utes with the appropriate staining reagents using a standard method as described previously (9). In brief, the cells were stained with FITC-labeled anti-CD8, anti-TCR- $\beta$, anti-CD3 $\varepsilon$, anti-CD69, anti-CD44 mAb (IM7; BD-PharMingen, San Diego, California, USA), anti-IL-4R $\alpha$ mAb (Genzyme Pharmaceuticals, Cambridge, Massachusetts, USA), or anti-common- $\gamma \mathrm{mAb}$ (4G3; BD-PharMingen), followed by anti-rat Ig-FITC. Then the cells were stained with anti-CD4-PE (antiCD4-phycoerythrin) (GK1.5-PE; BD-PharMingen). For anti-common- $\gamma$ staining, anti-CD4-PE was added after residual reactive sites of the anti-rat Ig-FITC were blocked with normal rat serum. For bone marrow-derived mast cell (BMMC) staining, FITC-labeled anti-c-kit mAb (BD-PharMingen) and IgE (SPE-7; Sigma-Aldrich, St. Louis, Missouri, USA), followed by FITC-labeled anti-IgE mAb (BD-PharMingen), were used. Flow cytometry analysis was performed on a FACSCalibur (Becton Dickinson Immunocytometry Systems, Mountain View, California, USA), and the 
results were analyzed using CellQuest software (Becton Dickinson Immunocytometry Systems).

Immunoprecipitation and immunoblotting. Immunoprecipitation and immunoblotting were performed as described previously (10). The reagents used were antiserum specific for STAT6 (R\&D Systems Inc., Minneapolis, Minnesota, USA) and polyclonal antibodies against SHP-1 (Santa Cruz Biotechnology Inc., Santa Cruz, California, USA), Erk1, and Erk2 (BioLabs Inc., Beverly, Massachusetts, USA). Isotype-matched Ig's (BD-PharMingen) were used as controls. For Erk1 and Erk2 phosphorylation, naive CD4 T cells were purified with anti-CD4 mAb (RM4-5) and magnetic bead sorting (MACS sorting), and then the cells were incubated with anti-TCR $\mathrm{mAb}$ (H57-597) and additional anti$\mathrm{CD} 4 \mathrm{mAb}(\mathrm{RM} 4-5)$ at $4^{\circ} \mathrm{C}$. After incubation, the cells were stimulated with anti-hamster Ig's (which crossreact with both H57-597 and RM4-5) for 5, 15, 30, and 60 minutes at $37^{\circ} \mathrm{C}$, and then total cell lysates were subjected to phospho-Erk immunoblotting. To assess IL-4-induced tyrosine phosphorylation, naive CD4 T cells from $m e /+$ mice and littermates were stimulated with IL-4 $(100 \mathrm{U} / \mathrm{ml})$ for 10,60 , and 120 minutes at $37^{\circ} \mathrm{C}$. Anti-phosphotyrosine mAb (RC20; Transduction Laboratories, Lexington, Kentucky, USA) was used for detection.

T cell purification and Th1/Th2 cell differentiation in vitro. Naive (CD44-) CD4 ${ }^{+} \mathrm{T}$ cells from the spleen were prepared as follows. Splenocytes were incubated with culture supernatant of both anti-CD8 (53-6.72) and antiCD44 (IM7) mAb's (BD-PharMingen). The treated cells were washed and then incubated on plastic dishes coated with goat anti-mouse IgGs (catalog no. 55455; Cappel Research Products, Durham, North Carolina, USA) that cross-react with rat IgG, including 53-6.72 and IM7 (10). The nonadherent cells were used as a naive $\mathrm{CD} 44^{-} \mathrm{CD} 4^{+} \mathrm{T}$ cell population. Flow cytometry analysis revealed that contamination of $\mathrm{CD} 44^{+}$cells and CD8 T cells was less than $3 \%$. Half a million enriched naive CD4 T cells were stimulated for 2 days with 0.3 or $1 \mu \mathrm{g} / \mathrm{ml}$ immobilized anti-TCR mAb (H57-597) in the presence of $20 \mathrm{U} / \mathrm{ml} \mathrm{IL-2}$ and 1 or $3 \mathrm{U} / \mathrm{ml} \mathrm{IL-4}$ (Th2skewed condition), or in the presence of $20 \mathrm{U} / \mathrm{ml} \mathrm{IL}-2$, 1 or $10 \mathrm{U} / \mathrm{ml} \mathrm{IL}-12$, and anti-IL-4 mAb (11B11, 12.5\% culture supernatant) (Th1-skewed condition). Then, the cells were cultured only with cytokines for another 3 days. Cultured $\mathrm{T}$ cells were restimulated with anti$\mathrm{TCR} \mathrm{mAb}(30 \mu \mathrm{g} / \mathrm{ml})$ for 6 hours in the presence of 2 $\mu \mathrm{M}$ monensin, which inhibits the secretion of newly produced protein. Intracellular staining of IL-4 and IFN- $\gamma$ was performed as described previously (10).

ELISA for the measurement of cytokine concentration. Naive CD4 T cells were stimulated with immobilized antiTCR $(3 \mu \mathrm{g} / \mathrm{ml})$ in 24 -well flat-bottom plates $\left(2 \times 10^{5}\right.$ cells per well) for various times at $37^{\circ} \mathrm{C}$. The production of IL- 4 or IL- 5 was assessed by ELISA as described previously (52). The production of IL-13 was evaluated with a mouse IL-13 ELISA kit (R\&D Systems Inc.) according to the manufacturer's protocol.
Assessment of the mast cell function. Bone marrow cells of $\mathrm{me} /+$ and wild-type mice were cultured in complete RPMI 1640 medium supplemented with $10 \mathrm{ng} / \mathrm{ml}$ recombinant murine IL-3 (Genzyme Pharmaceuticals) at $5 \times 10^{5}$ nucleated cells per milliliter. Culture medium was exchanged every 7 days. Four weeks later, most of the cultured cells were c-kit ${ }^{+}$and IgE-reactive and were used as BMMCs. To stimulate the BMMCs with $\operatorname{IgE}$ plus antigen, we preloaded $5 \times 10^{5}$ cells with $5 \mu \mathrm{g} / \mathrm{ml}$ anti-dinitrophenyl (anti-DNP) IgE (SPE-7) for 2 hours on ice, washed them three times to remove unbound $\operatorname{IgE}$, and then incubated them with various concentrations of DNP-BSA (25-35 mol DNP/mol BSA; LSL Co., Tokyo, Japan) in a 48-well plate. After 24 hours of incubation, supernatants were collected and the concentration of cytokines was determined by ELISA.

Sensitization and inhalation with OVA. me/+ and wild-type mice ( $\mathrm{C} 3 \mathrm{HeB} / \mathrm{Fej}-\mathrm{a} / \mathrm{a}$ background) were immunized intraperitoneally with $250 \mu \mathrm{g}$ OVA (chicken egg albumin from Sigma-Aldrich) in $4 \mathrm{mg}$ aluminum hydroxide gel (alum) on day 0 and day 7. Mice were made to inhale aerosolized OVA in saline $(10 \mathrm{mg} / \mathrm{ml})$ for 30 minutes using a supersonic nebulizer (model NE-U07; Omron Co., Tokyo, Japan) on day 14 and day 16 for assessment of eosinophilic inflammation, or on days 19, 20, and 21 for the evaluation of airway hyperresponsiveness. Reproducible OVA inhalation-dependent eosinophilic inflammation and airway hyperresponsiveness were induced in wild-type mice using this approach.

Collection of BAL fluid and lung histology. Two days after the last OVA inhalation on day 16, BAL was performed as described previously (53). Total BAL fluid was collected, and cells in 100- $\mu \mathrm{l}$ aliquots were counted. One hundred thousand viable BAL cells were cytocentrifuged onto slides by a Cytospin3 (Thermo Shandon Ltd., Runcorn, United Kingdom) and stained with May-Gruenwald Giemsa solution (MERCK, Darmstadt, Germany) as described previously (46). Two hundred leukocytes were counted on each slide. Cell types were identified using morphological criteria. The percentages of each cell type were calculated.

For lung histology, mice were sacrificed by $\mathrm{CO}_{2}$ asphyxiation 48 hours after the last OVA inhalation on day 16 , and the lungs were infused with $10 \%$ (vol/vol) formalin in PBS for fixation. The lung samples were sectioned, stained with hematoxylin and eosin reagents or periodic acid-Schiff (PAS) reagent, and examined for pathological changes under a light microscope at $\times 100$ and $\times 200$. Numbers of infiltrated mononuclear cells in the perivascular and peribronchiolar regions were calculated by direct counting of four different fields per slide.

Measurement of airway byperresponsiveness. Airway responsiveness was assessed by methacholine-induced airflow obstruction of conscious mice placed in a whole-body plethysmograph (model PLY3211; Buxco Electronics Inc., Troy, New York, USA) as described previously (54). The respiratory parameters were obtained by exposure of mice to $0.9 \%$ saline mist, followed by 
incremental doses $(1-30 \mathrm{mg} / \mathrm{ml})$ of aerosolized methacholine. Airflow obstruction was monitored and analyzed by system XA software (model SFT1610; Buxco Electronics Inc.). The results are expressed as the average percentage of base-line enhanced-pause values after $0.9 \%$ saline exposure.

\section{Results}

Phenotypically normal naive CD4 T cells develop in me/+ mice. The goal of this study was to clarify the role of SHP-1 molecules in Th1/Th2 cell differentiation and the development of Th2-dependent allergic responses, such as allergic asthma. Impaired differentiation and functional abnormalities in cells of hematopoietic lineage have been reported in the motheaten (me/me) mouse, in which SHP-1 molecules are deficient (12). We initiated the analysis of $\mathrm{T}$ cell development by assessing the expression of cell surface differentiation molecules on thymocytes and splenic T cells. Representative CD4/CD8 profiles of wild-type and me/+ mice with the motheaten mutation are shown in Figure 1a. The percentages of CD4 and CD8 T cells in the spleen were similar between wild-type and heterozygous mice. Likewise, the thymocyte $\mathrm{CD} 4 / \mathrm{CD} 8$ profiles observed in me/+ mice and wild-type mice were similar. The yields of spleen cells and thymocytes in heterozygous mice were similar to those in wild-type controls. As reported previously, significant reductions in the number of CD4 and CD8 T cells in the spleen of homozygous $(\mathrm{me} / \mathrm{me})$ mice were observed (data not shown). In addition, growth retardation was prominent within a few weeks after birth in homozygous mice (data not shown). These results indicate that homozygous $m e / m e$ mice are not suitable for assessment of peripheral CD4 $\mathrm{T}$ cell function.

Next, the cell surface expression of TCR- $\beta$, CD $3 \varepsilon$, CD44, CD69, and CD25 on splenic CD4 T cells in $m e /+$ mice was examined. No abnormalities were detected (data not shown). Since IL-4R is critical for Th2 2 cell differentiation (55), and a recent study had suggested that SHP-1 is required for IL-4-induced IL-4R expression (56), we determined the expression levels of common- $\gamma$ chain and IL-4R $\alpha$ chain. These were found to be similar in the $m e /+$ mice even after IL-4 exposure in vitro (Figure 1b).

We then assessed the expression of SHP-1 protein in splenic CD4 $\mathrm{T}$ cells in $m e /+$ mice by immunoblotting with an anti-SHP-1 antibody and found that the amount of SHP-1 protein in me/+ CD4 T cells appeared to be lower by about one-half to one-third (Figure 1c). The levels of expression of CD3E protein as assessed using an anti-CD $3 \varepsilon \mathrm{mAb}(1352.9)$ were not decreased in $m e /+$ mice (data not shown). Based on these results, we decided to use me/+ mice to investigate the role of SHP-1 protein in Th1/Th2 cell differentiation and the development of allergic asthma.

$T C R$ - and IL-4R-mediated signal transduction in splenic CD4 T cells from me/+ mice. It has been suggested that SHP-1 acts as a negative regulator of TCR- and

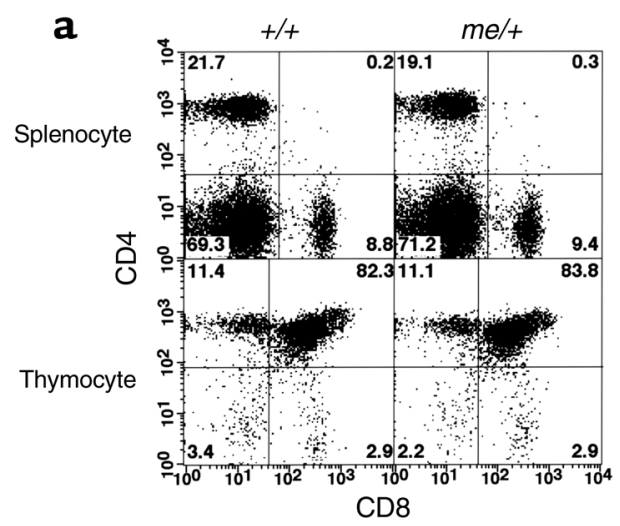

b
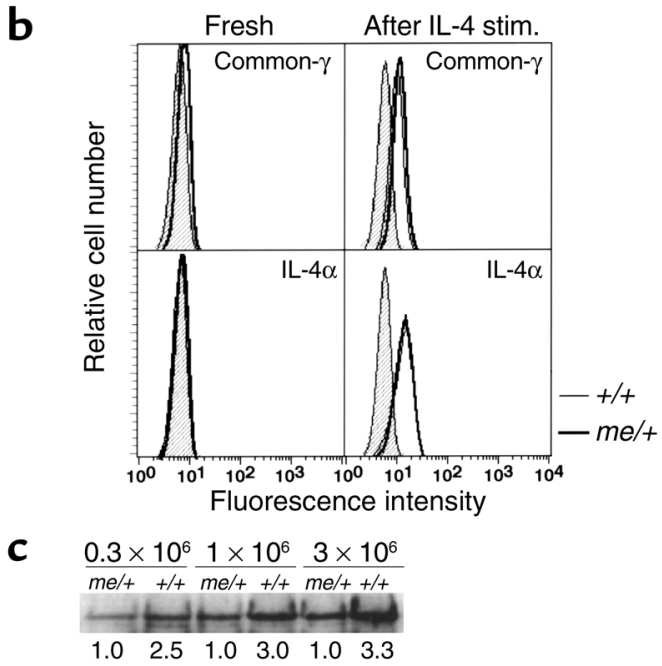

Figure 1

Phenotypically normal naive CD4 T cells developed in me/+ mice. (a) Representative CD4/CD8 profiles of splenocytes and thymocytes of wild-type $(+/+)$ and heterozygous $(m e /+)$ mice with the motheaten mutation. The percentages of cells in each quadrant are shown. The numbers of cells harvested (yield) were $1.41 \times 10^{8}$ splenocytes in wild-type, $1.52 \times 10^{8}$ splenocytes in $\mathrm{me} /+, 1.72 \times 10^{8}$ thymocytes in wild-type, and $1.70 \times 10^{8}$ thymocytes in $\mathrm{me} /+$. (b) Splenic CD4 T cells from wild-type and $m e /+$ mice were cultured with IL-4 (100 $\mathrm{U} / \mathrm{ml}$ ) for 24 hours, and the expression of common- $\gamma$ and IL- $4 \mathrm{R} \alpha$ chain was assessed. Background staining is shown as hatched areas. (c) SHP-1 protein expression in splenic CD4 T cells from me/+ and wild-type mice. Immunoprecipitation and immunoblotting with anti-SHP-1 mAb were performed. Ratios of the intensities of the SHP-1 bands are shown.

cytokine receptor-mediated signal transduction. Therefore, we assessed alterations in signaling downstream of TCR and IL-4R in naive CD4 T cells from me/+ mice, in which the levels of SHP protein are reduced. $\left[\mathrm{Ca}^{2+}\right]_{\mathrm{i}}$ mobilization in $\mathrm{CD} 4 \mathrm{~T}$ cells from wildtype and $m e /+$ mice monitored after TCR or TCR/CD4 cross-linking showed no difference in the percentages of responding cells and the magnitude of the responding cells (data not shown). Next, to assess the levels of activation of the ERK MAPK cascade, naive CD4 T cells from wild-type and $m e /+$ mice were stimulated with anti-TCR and anti-CD4 mAb, and then the tyrosine phosphorylation of Erk1 and Erk2, reflecting MAPK 
kinase (MAPKK) activation, was examined. Slight increases in the peak level of phosphorylation of both Erk1 and Erk2 were detected. The phosphorylation level in cells before stimulation (time 0) was significantly increased (Figure 2a). However, there was no difference between wild-type and $m e /+$ mice with respect to the relative increase in response to stimulation. Also, no obvious sustained phosphorylation was observed. Although SHP-1 is reported to be required for IL-4induced IL-4R expression (56), no significant difference was detected between $m e /+$ and wild-type mice (Figure 1b). Interestingly, however, the levels of IL-4-induced STAT6 phosphorylation were doubled at 10 minutes and remained at sustained levels even at 120 minutes following IL-4 stimulation (Figure 2b). The levels of STAT6 protein in naive CD4 T cells from me/+ mice were within the normal range. Thus, IL-4R-mediated signaling in naive $\mathrm{CD} 4 \mathrm{~T}$ cells appears to be affected in $m e /+$ mice, perhaps as a consequence of the lower levels of SHP-1 protein.

Increased Th2 cell development in me/+ mice. The development of Th1 and Th2 cells from naive CD $4 \mathrm{~T}$ cells in wild-type and $m e /+$ mice was assessed using an in vitro Th1/Th2 cell differentiation system (9). Naive CD4 T cells were stimulated with $1 \mu \mathrm{g} / \mathrm{ml}$ of immobilized antiTCR $\mathrm{mAb}$ in the presence of IL-4 or IL-12 (Figure 3). Significant numbers of Th2 cells were generated in wild-type cultures, and, as expected, increased Th2 cell generation was observed in $\mathrm{me} /+$ cultures. The percentages of IFN- $\gamma^{+} \mathrm{IL}-4^{+}$cells were also slightly increased in $m e /+$ cultures. However, IL-12-dependent Th1 cell generation was not significantly increased. The absolute numbers of harvested cells in the 5-day Th1/Th2 cell differentiation cultures were similar under these conditions (data not shown). These results suggest that Th2 cell differentiation is significantly enhanced in $m e /+\mathrm{CD} 4 \mathrm{~T}$ cells.

Increased Th2 cytokine production in me/+ mice. Freshly prepared CD4 $\mathrm{T}$ cells from wild-type and me/+ mice were stimulated in vitro with immobilized anti-TCR $\mathrm{mAb}$ for different amounts of time, and the production of Th2 cytokines (IL-4, IL-5, and IL-13) in the culture supernatant was determined by ELISA. The anti-TCR-induced IL-4 production was significantly increased at all time points tested (Figure 4a). The production of IL-13 was first detected 36-48 hours after stimulation, and levels of IL-13 rose significantly thereafter in $m e /+$ cultures (Figure $4 \mathrm{~b}$ ). A significant amount of IL-5 was first detected at the 72-hour time point in wild-type mice, whereas IL-5 production was detected as early as 48 hours in $m e /+$ mice (Figure $4 c$ ). Moreover, a significant enhancement was detected at the 72-hour time point. These results suggest that the production of Th 2 cytokines is increased in naive $\mathrm{CD} 4 \mathrm{~T}$ cells of $m e /+$ mice in comparison with wildtype mice. The levels of the anti-TCR-induced Th1 cytokine IFN- $\gamma$ showed slight decreases in $m e /+$ mice, but these were not significant (at the 12-hour time point, $686 \pm 114 \mathrm{pg} / \mathrm{ml}$ in $m e /+$ mice vs. $931 \pm 42$ in wild-type mice, $P>0.1$; at the 24-hour time point, $9,005 \pm 69 \mathrm{pg} / \mathrm{ml}$ in $\mathrm{me} /+$ mice vs. 9,300 \pm 436 in wildtype mice, $P>0.5$ ).

To examine antigen-specific stimulation, we immunized wild-type and $m e /+$ mice with OVA-alum and boosted them with OVA-alum on day 7. Two weeks later, spleen cells were prepared and cultured for 3 days with OVA $(10 \mu \mathrm{g} / \mathrm{ml})$ for evaluation of cytokine production. Modest Th2-skewed responses were detected (IL-4, undetectable; IL-5, $55.5 \pm 8.5 \mathrm{pg} / \mathrm{ml}$ in me/+ mice vs. undetectable in wild-type mice; and IFN- $\gamma, 1,163 \pm 450 \mathrm{pg} / \mathrm{ml}$ in $m e /+$ mice vs. $1,452 \pm 735$ in wild-type mice). Thus, the increased Th2 cytokine pattern in $m e /+$ mice is demonstrated following antigen-specific stimulation.

We examined the OVA-specific IgG1 and IgE production in the serum of me/+ and wild-type mice (C3H background) with two OVA-alum immunizations, but under this condition, OVA-specific IgG1 and $\operatorname{IgE}$ were undetectable (data not shown). In order to detect OVA-specific antibody production more effectively, we mated $m e /+$ mice (C3H background) with OVA-specific TCR- $\alpha \beta$ Tg mice (BALB/c background) and used the offspring for immunization studies. Two weeks after the last OVA immunization, OVA-specific IgG1 and IgE in the serum were assessed. Slightly increased responses were detected in

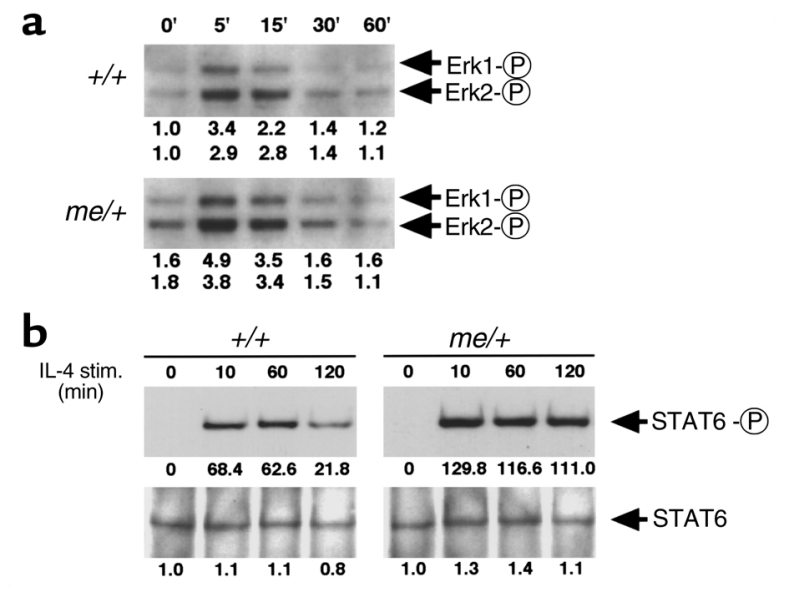

\section{Figure 2}

TCR-induced MAPKK activation and IL-4-induced STAT6 phosphorylation in splenic CD4 T cells from me/+ mice. (a) Phosphorylation status of Erk1 and Erk2 in splenic CD4 T cells was assessed 5-60 minutes after co-cross-linking of TCR and CD4 molecules. The cells were lysed, and the lysates were subjected to immunoblotting with anti-phospho-Erk antibody. Densitometric measurements of the phosphorylated bands (p44 for Erk1 and p42 for Erk2) are shown under each band in arbitrary units. Erk1-P, phospho Erk-1. (b) IL-4induced phosphorylation of STAT6. Splenic CD4 T cells from wildtype and $\mathrm{me} /+$ mice were stimulated with IL-4 $(100 \mathrm{U} / \mathrm{ml})$ at $37^{\circ} \mathrm{C}$ for the indicated times. The cell lysates were subjected to immunoprecipitation with anti-STAT6 antiserum, and to immunoblotting with anti-phosphotyrosine mAb (upper panel) or anti-STAT6 antiserum (lower panel). Densitometric measurements of the phosphorylated STAT6 bands and STAT6 protein bands are shown under each band in arbitrary units. STAT6-P, phospho-STAT6. 


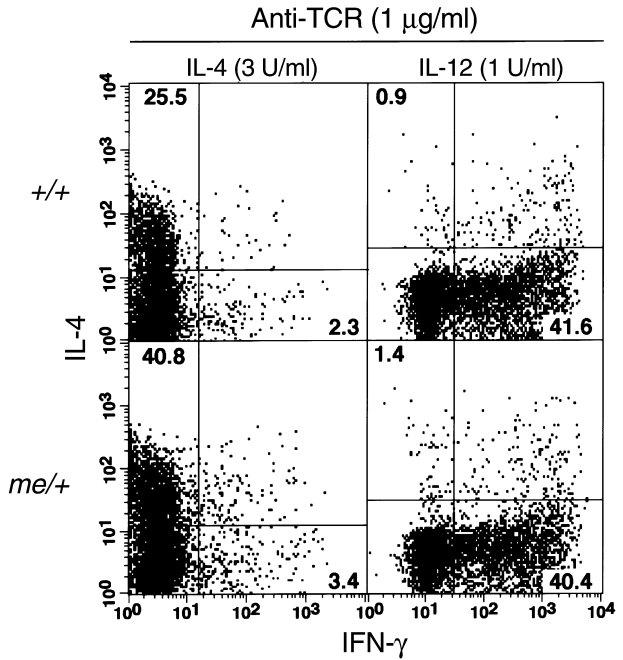

Figure 3

Increased Th2 cell differentiation in $\mathrm{me} /+$ naive CD4 T cells. Naive CD4 T cells from wild-type and $m e /+$ mice were stimulated for 5 days with immobilized anti-TCR- $\beta \mathrm{mAb}(1 \mu \mathrm{g} / \mathrm{ml})$ in the presence of 20 $\mathrm{U} / \mathrm{ml}$ exogenous IL-2 and $3 \mathrm{U} / \mathrm{ml} \mathrm{IL-4}$ (Th2-skewed condition) or 1 $\mathrm{U} / \mathrm{ml} \mathrm{IL-12}$ and anti-IL-4 mAb (Th1-skewed condition). The generation of Th 1 and Th2 cells was assessed by cytoplasmic staining with IFN- $\gamma$ and IL-4. The absolute numbers of cells harvested were similar in these cultures. The percentages of cells in each quadrant are shown. Four independent experiments were performed with similar results.

$m e /+$ mice $(\operatorname{IgG} 1,4,050 \pm 297 \mu \mathrm{g} / \mathrm{ml}$ in $m e /+$ mice vs. $2,677 \pm 411 \mu \mathrm{g} / \mathrm{ml}$ in wild-type mice, $P=0.0269 ; \mathrm{IgE}$, $1,660 \pm 224 \mu \mathrm{g} / \mathrm{ml}$ in $m e /+$ mice vs. $882 \pm 146 \mu \mathrm{g} / \mathrm{ml}$ in wild-type mice, $P=0.0272$ ). Thus, although the effect was quite modest in the OVA-specific TCR- $\alpha \beta$ $\mathrm{Tg}$ system, antigen-specific Th2-skewed immune responses appeared to be enhanced in the $m e /+$ mice.

Enhanced IL- 6 and IL-13 production of BMMCs in me/+ mice. BMMCs from wild-type and me/+ mice were prepared as described in Methods. The phenotypic features were indistinguishable between wild-type and $m e /+$ in terms of c-kit expression and IgE binding capacity (Figure 5a). Stimulation of mast cells by cross-linking of FceRI with anti-DNP IgE and DNP-BSA was performed to assess IL-4, IL-5, IL-6, IL-13, and TNF- $\alpha$ production. Significant amounts of IL- 6 and IL-13 in the culture supernatant were detected; however, the production of IL-4, IL-5, and TNF- $\alpha$ was undetectable. The levels of both cytokines (IL-6 and IL-13) appeared to be greater in $m e /+$ BMMCs than in wild-type (Figure 5b).

Enhanced OVA-induced asthma phenotype in me/+ mice. The results thus far suggest that Th2 cell differentiation and Th2 cytokine production in CD4 T cells and specific cytokine production in mast cells are enhanced in me/+ mice that express reduced amounts of the SHP-1 protein. Consequently, we wished to examine the role of SHP-1 in antigen-induced Th2-dependent inflammation in vivo and selected the OVA-induced allergic airway inflammation model. Wild-type and me/+ mice were immunized twice with OVA-alum, and, 2 weeks later, mice were treated with inhaled OVA as described in Methods. BAL fluid was harvested and examined for infiltrating cells (Figure 6, a and b). The numbers of total cells were increased significantly in $m e /+$ mice (Figure $6 \mathrm{a}$, far right columns). The absolute numbers of eosinophils, lymphocytes, neutrophils, and macrophages were determined by cell counting based on morphological criteria, and the percentages of each cell type were calculated. Significant increases in both the absolute number (Figure 6a) and the percentage (Figure $6 \mathrm{~b})$ of eosinophils were observed. In the me/+ mice not subjected to either OVA sensitization or OVA inhalation, no infiltrating cells were detected in the BAL fluid (data not shown).

Concurrently, histological changes in the lungs of $m e /+$ mice were evaluated by $\mathrm{H} \& \mathrm{E}$ staining (Figure 6 , $c-h)$. No inflammatory cell infiltration was noted in the lungs of PBS-treated wild-type and me/+ mice (Figure $6, \mathrm{c}$ and $\mathrm{f}$ ). With antigen challenge, the levels of inflammatory mononuclear cell infiltration in the peribronchiolar region were significantly augmented, and inflammatory mononuclear cell infiltration was extended to the surrounding area in $m e /+$ mice (arrows in Figure 6, $g$ and $h$ ) in comparison with infiltration observed in wild-type mice (open arrowheads in Figure $6, \mathrm{~d}$ and e). PAS staining was performed to examine the levels of mucus hyperproduction. Representative bronchiolar profiles of alum-treated me/+ mice, OVA-sensitized and inhaled OVA-treated wild-type mice, and OVA-sensitized and inhaled OVA-treated $\mathrm{me} /+$ mice are shown in Figure 6, i-k. Essentially no specific staining was detected in alum-treated me/+ lung (Figure 6i). Mild staining in wild-type bronchioles was noted (Figure $6 \mathrm{j}$ ), whereas the staining levels were increased in $m e /+$ bronchioles (Figure 6k), indicating mucus hyperproduction in $m e /+$ lung. A significant increase in the levels of airway inflammation and goblet cell hyperplasia was also detected in a more intense inhalation protocol (days 19, 20, and 21; data not shown). Taken together, these results suggest that the OVA-induced asthma phenotype is enhanced in $m e /+$ mice.

Enhanced airway hyperresponsiveness to methacholine in me/+ mice. Finally, to assess the extent of airway hyper-

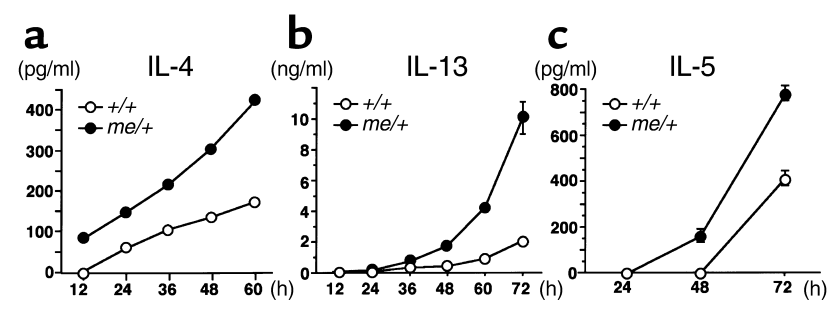

\section{Figure 4}

Increased Th2 cytokine production in me/+ T cells. Splenic CD4 T cells were stimulated with immobilized anti-TCR- $\beta$ for the indicated times, and the concentrations of cytokines ( $\mathbf{a}, \mathrm{IL}-4 ; \mathbf{b}, \mathrm{IL}-13$; and $\mathbf{c}$, $\mathrm{IL}-5$ ) in the culture supernatant were determined by ELISA. Mean values and standard deviations are shown. In several cases, the deviations are too small to be visible. Three independent experiments were performed, and similar results were obtained. 
responsiveness, $m e /+$ mice were immunized and made to inhale OVA. Airway hyperresponsiveness was assessed by measurement of methacholine-induced airflow obstruction in a whole-body plethysmograph. As shown in Figure 7a, the degree of hyperresponsiveness was significantly enhanced at doses of 10 and 30 $\mathrm{mg} / \mathrm{ml}$ methacholine in $m e /+$ mice. Next, $m e /+$ and wild-type mice were treated with PBS, alum, or OVAalum on day 0 and day 7 . On days 14 and 16, half of the OVA-sensitized mice were made to inhale OVA. Then, methacholine-induced airflow obstruction was measured (Figure 7b). The enhanced airway hyperresponsiveness was noted in the OVA-sensitized me/+ mice only after OVA inhalation, suggesting an OVA-inhalation dependency. Also, the base-line airway responsiveness was similar between $m e /+$ and wild-type mice. Thus, the development of OVA-induced airway hyperresponsiveness in a mouse experimental asthma model appeared to be dependent in part on SHP-1 levels.

\section{Discussion}

In this report, the role of SHP-1 molecules in Th1/Th2 cell differentiation and the development of Th2dependent allergic responses were investigated. We used me/+ mice, in which CD4 $\mathrm{T}$ cells express about half the amount of SHP-1 protein that those of wildtype mice express. In an experimental OVA-induced allergic airway inflammation model, eosinophilic infiltration and airway hyperresponsiveness were found to be enhanced in $m e /+$ mice, suggesting that the protein level of SHP-1 may control the pathogenesis of allergen-induced airway inflammation.

Antigen recognition by $\mathrm{T}$ cells induces the recruitment of a series of signaling molecules into lipid rafts and generates a cascade of biochemical events involving tyrosine phosphorylation of target proteins, leading to T cell activation $(57,58)$. Conversely, the dephosphorylation reaction of tyrosine-phosphorylated proteins is carried out by protein tyrosine phosphatases (PTPs). A dynamic balance between positive and negative regulatory mechanisms is important for maintaining the threshold at which antigens trigger $\mathrm{T}$ lymphocyte activation (59). Equally important, but less well understood, are the mechanisms that negatively regulate signal transduction. PTPs, including SH2 domaincontaining tyrosine phosphatases, are increasingly being shown to play key roles in T cell development and signaling (13). SHP-1 downregulates TCR-induced activation by dephosphorylating src-family PTKs, such as Lck and Fyn (28), as well as ZAP-70 kinase $(29,60)$. In addition, Jak 1 and Jak 3 tyrosine kinases, which mediate the signals of the IL-4R and IL-13R, were reported to be targets of SHP-1 (38).

In the present study, we first assessed the effect of decreased amounts of SHP-1 on the signal transduction capacity of both TCR and IL-4R in naive CD4 T cells, using me/+ mice (Figure 2 ). The changes were not dramatic, probably because the reduction in SHP-1 expression was at most about one-third in me/+ mice.
A significantly prolonged IL-4-induced STAT6 activation was observed, while the effects on TCR-induced signaling were modest at best. However, even with this level of change in signaling, Th2 cell differentiation and Th2 cytokine production were enhanced significantly in these mice (Figures 3 and 4). Similarly, OVAinduced eosinophilic airway inflammation and hyperresponsiveness were consistently found to be enhanced (Figures 6 and 7). These results suggest that allergeninduced eosinophilic airway inflammation and hyperresponsiveness are highly dependent on IL-4-induced STAT6 activation $(42-44,48)$, and on the SHP-1-mediated downregulation of the activated signaling cascade. We observed no significant change in IL-12-induced Th1 cell differentiation in spite of the reduced SHP-1 levels in $m e /+\mathrm{T}$ cells (Figure 3 ). This suggests that Th1 cell differentiation is less sensitive to SHP-1 levels.

In the experimental OVA-induced allergic airway inflammation model, eosinophilic infiltration and airway hyperresponsiveness are known to be dependent on the generation of OVA-specific Th2 cells (41-43). Thus, it is most likely that the enhanced asthma phenotype in $m e /+$ mice can be ascribed to the increased generation of antigen-specific Th2 cells. However, it is also possible that the levels of inflammation also depend on decreased SHP-1 protein in other inflam-
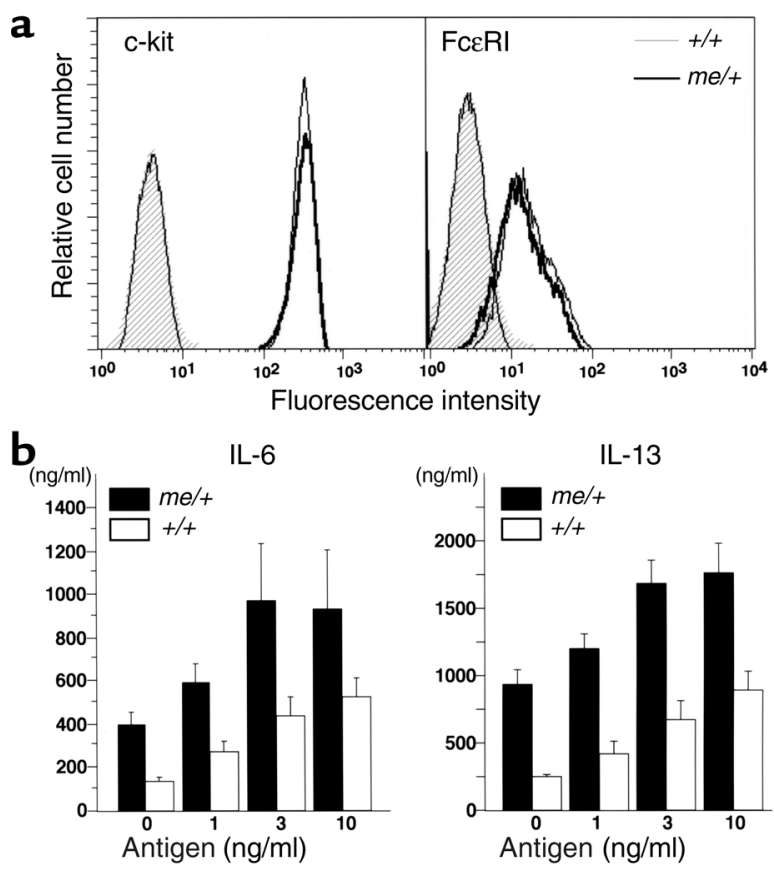

Figure 5

Increased IL-6 and IL-13 production of BMMCs from $\mathrm{me} /+$ mice. (a) $c$-kit expression and IgE binding capacity of BMMCs prepared from wild-type and $m e /+$ mice. Shaded areas represent background staining. (b) Cross-linking stimulation of FceRI was performed by antiDNP IgE and DNP-BSA. The production of IL- 6 and IL-13 in the culture supernatant was assessed by ELISA. Mean values + SD are shown. $P$ values of IL- 6 data, from left $(0 \mathrm{ng} / \mathrm{ml}$ stimulation $)$ to right $(10 \mathrm{ng} / \mathrm{ml}$ stimulation $)$, are $0.001,0.004,0.027$, and 0.068 , and those of IL-13 data are $0.0004,0.0006,0.0012$, and 0.0047 . 

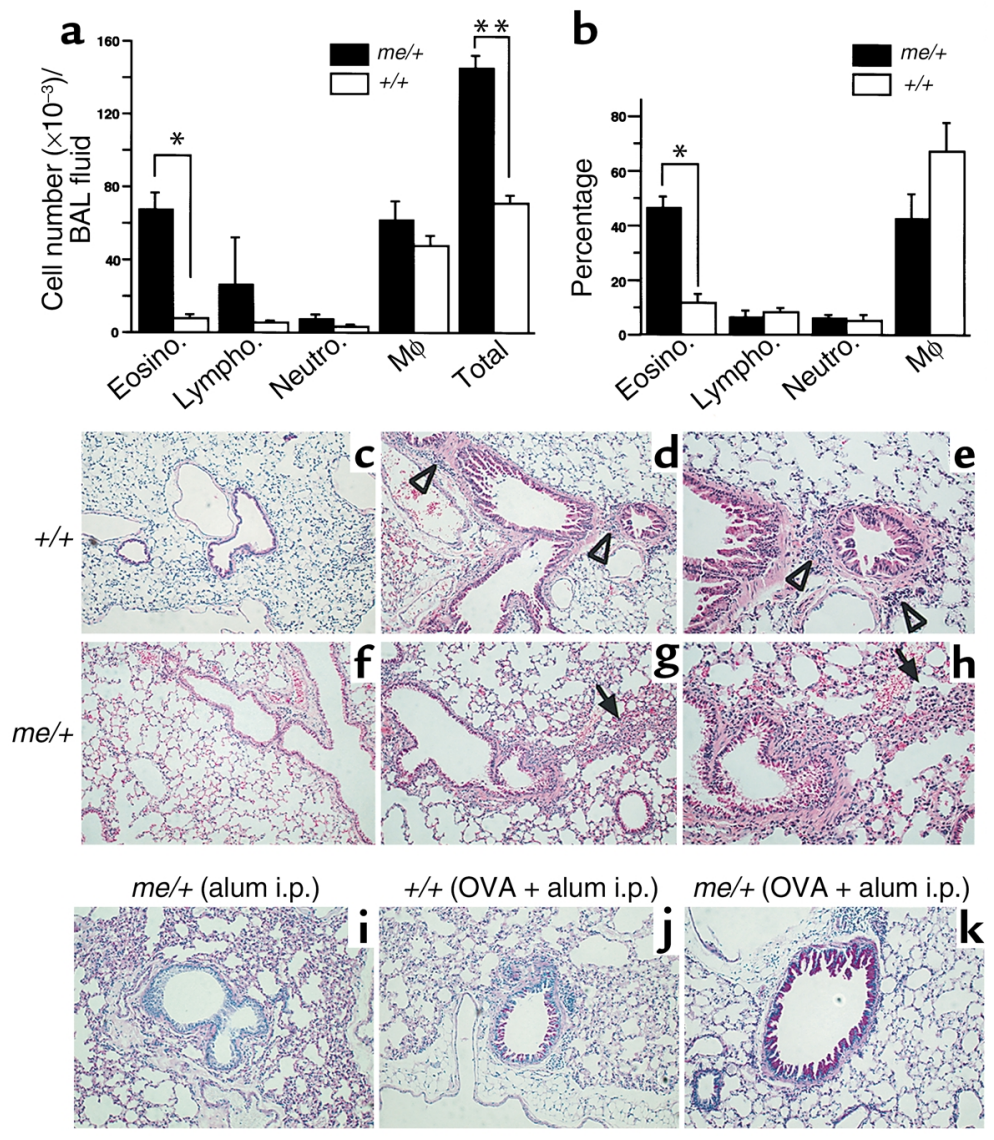

\section{Figure 6}

OVA-induced eosinophilic infiltration in BAL fluid and airway inflammation in $m e /+$ mice. The absolute cell number (a) and percentage (b) of eosinophils (Eosino.), lymphocytes (Lympho.), neutrophils (Neutro.), and macrophages (M $\phi)$ in BAL fluid are shown with SDs. Seven wild-type mice and eight $m e /+$ mice were used in this experiment. The results were obtained using the values of cell counting, percentage of the cells, total cell number per milliliter, and volume of BAL fluid recovered. ${ }^{*} P<0.0005$, ${ }^{*} P<0.0001$, and other $P$ values $>0.04$ by Student $t$ test. $(\mathbf{c}-\mathbf{h})$ Eight-week-old wild-type mice (c-e) and $m e /+$ mice $(\mathbf{f}-\mathbf{h})$ were used. (d, e, g, and h) OVA immunization and inhalation with OVA aerosol were done as in $\mathbf{a}$. (c and f) Control treatment with PBS was also done. The lungs were fixed and stained with hematoxylin and eosin. $\times 100, \mathbf{c}, \mathbf{d}, \mathbf{f}$, and $\mathbf{g}$; $\times 200$, e and $\mathbf{h}$. Sections shown are representative of ten lung sections per mouse from five mice in each group. Peribronchiolar mononuclear cell infiltrates are noted in the wild-type control groups (open arrowheads in $\mathbf{d}$ and $\mathbf{e}$ ). The infiltrate was extended in $\mathrm{me} /+$ mice (arrows in $\mathbf{g}$ and $\mathbf{h}$ ). Numbers of infiltrated mononuclear cells in the perivascular and peribronchiolar regions were $159.3 \pm 17.0$ in the $m e /+$ and $77.3 \pm 10.7$ in the wild-type group. (i-k) Lungs from $m e /+$ mice immunized with alum alone and without OVA inhalation (i), wild-type mice treated with OVA-alum immunization and OVA inhalation (j), and $m e /+$ mice treated with OVA-alum immunization and OVA inhalation (k) were stained with PAS. A representative staining pattern in each group is shown. $\times 100$. i.p., intraperitoneally.

matory cells, such as mast cells and eosinophils. The role of mast cells in OVA-induced allergic airway inflammation and airway hyperresponsiveness is controversial (61-63). Takeda et al. reported that both airway inflammation and hyperresponsiveness were intact in mast cell-deficient mice (61). However, Williams et al. reported that mast cells can amplify both airway inflammation and hyperresponsiveness in a different experimental system using OVA sensitization without adjuvant (62). Kobayashi et al. reported experimental results that support an essential role of mast cells in airway hyperresponsiveness (63). Here, we detected increased production of IL- 6 and IL-13 from me/+ BMMCs upon FceRI cross-linking (Figure 5b). IL-13 is reported to be important for the induction of airway hyperresponsiveness (64-66). Thus, although more comprehensive analysis is required, it is likely that enhanced function of $m e /+$ mast cells contributes to the increased airway hyperresponsiveness in $m e /+$ mice. As for other inflammatory cells such as eosinophils, little is known about the dependence on SHP-1 of their activation and function at this time. Further studies are required to address which cell types are most critically affected by the reduced SHP-1 in me/+ mice. However, the present study clearly suggests that protein levels of SHP-1 control OVA-induced allergic airway inflammation and airway hyperresponsiveness.

Another SH2 domain-containing cytoplasmic PTP, SHP-2, is relatively ubiquitously expressed as compared with SHP-1, and it has been implicated in the positive regulation of lymphoid and hematopoietic cell development (67). However, the tyrosine phosphorylation levels of STAT1 following IFN- $\gamma$ and IFN- $\alpha$ treatment are significantly increased in SHP-2-deficient cells (36). Therefore, SHP-2 may also function as a negative regulator of the IFNstimulated Jak/STAT pathway. A newly characterized family of suppressor of cytokine signaling (SOCS) molecules are capable of inhibiting Jak/STAT pathways and may function as negative regulators for many cytokines signaling transduction (68). Consequently, some SOCS family members may control Th cell differentiation via the modification of cytokine signaling. In any event, these negative regulators may have roles in regulating Th 2 cell differentiation and the resulting Th2dependent immune responses.

Very recently, Deng et al. reported that SHP-1 controlled myelin basic protein-specific (MBP-specific) Th1 responses and severity of experimental autoimmune encephalomyelitis (EAE) (69). The conclusion appears to be contradictory to our observations; however, there are a few possible explanations for the different results. First, the systems used are very different. In order to induce Th2-dependent immune responses, we used alum adjuvant for OVA immunization. This is critical for the induction of suf- 
a
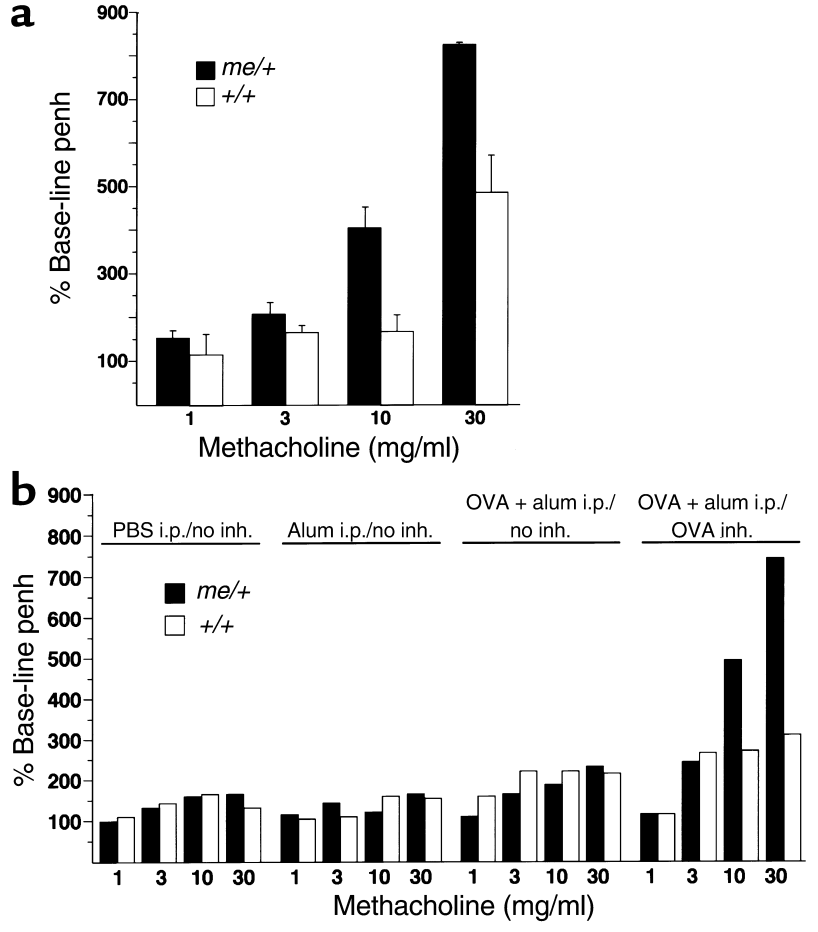

Figure 7

OVA-induced airway hyperresponsiveness in $m e /+$ mice. (a) Eightweek-old $m e /+$ mice sensitized with OVA were subjected to OVA inhalation on days 14 and 16. One day after the last OVA inhalation, airway hyperresponsiveness in response to increasing doses of methacholine was measured in a whole-body plethysmograph. Mean values of the percent above base line are shown with SDs for four mice. A total of four independent experiments were performed with similar results. $P>0.5$ for methacholine stimulation $(1 \mathrm{mg} / \mathrm{ml}$ and $3 \mathrm{mg} / \mathrm{ml})$, and $P<0.05$ for methacholine stimulation $(10 \mathrm{mg} / \mathrm{ml}$ and 30 $\mathrm{mg} / \mathrm{ml}$ ), by Student $t$ test. (b) Eight-week-old $m e /+$ mice were treated intraperitoneally with PBS, alum, or OVA-alum. Half of the mice with OVA-alum immunization were subjected to OVA aerosol on days 14 and 16 . On day 17, methacholine-induced airway hyperresponsiveness was measured. Mean values of the percent above base line are shown for a mouse in each group. Two sets of experiments were done with similar results. penh, enhanced pause. inh., inhalation.

ficient Th2-dependent allergic airway inflammation and airway hyperresponsiveness in various mouse strains. In contrast, in the EAE model, CFA was used to induce the appropriate MBP-specific Th1 responses (69). The second explanation relates to the mouse strains employed. It is well known that the preference to induce either Th1 or Th2 response can be dependent on the mouse strain that is used. We used me/+ mice on the $\mathrm{C} 3 \mathrm{H}$ background, whereas the mice used by Deng et al. were TCRV $\beta 8 \mathrm{Tg}$ and non-Tg on the B10.PL background, a strain that is susceptible to the induction of MBP-specific Th1 responses and EAE disease. Thus, our experimental system is more appropriate for the evaluation of the roles of SHP- 1 in the induction of Th2 2 cell differentiation and Th2 immune responses, and the Th1-disease models such as EAE appear to be more appropriate for the evaluation of Th1 immune responses. Third, the decrease in SHP-1 activity in T cells may be different between our me/+ mice and the viable $m e /+$ mice used by Deng et al. The viable motheaten mice possess a point mutation in the SHP- 1 molecule, and phosphatase activity of $m e^{\nu}$ SHP- 1 is diminished; however, the other molecular domains are normal. Thus, residual SHP-1 function may be sufficiently different between viable $m e /+$ mice and me/+ mice to account for the differential effects on Th1 and Th2 responses. It is likely that SHP- 1 can control both Th1 and Th2 responses and the corresponding diseases under certain conditions.

Recently the involvement of TLR4 in Th2 immune responses was reported (70). $\mathrm{C} 3 \mathrm{H} / \mathrm{HeJ}$ mice are deficient in TLR4. The observation is interesting; however, it is not known whether TLR4 deficiency is involved in the induction of Th2 responses and OVA-induced asthma phenotype in $m e /+$ mice.

From a clinical point of view, to treat allergic asthma, most strategies aim to block Th2 cell differentiation and the production of Th2 cytokines $(71,72)$. Previous infection with tuberculosis or measles has been reported to be associated with a reduced incidence of asthma (73). The administration of CpG oligodeoxynucleotides at the time of antigen sensitization appears to skew the inflammatory response toward Th1 $(74,75)$. Increased levels of IFN- $\gamma$ in the environment may shift the Th1/Th2 balance toward Th1, resulting in less severe allergic inflammation, although the clinical benefits have not yet been established. There have been reports of trials of humanized mAb's that bind to cytokines or their receptors, and also soluble receptors that bind to secreted cytokines (72). IL-4R antagonists given by nebulizer have shown some clinical benefits in asthmatic patients (76). Based on the current study, we propose that another strategy is to develop drugs that modify the signal transduction pathways required for Th2 2 cell differentiation. Reduced SHP-1 protein expression results in enhanced IL-4R-mediated signal transduction, Th2 cytokine production, and airway inflammation. Thus, SHP-1 could be a target signaling molecule for developing drugs for allergic asthma.

In summary, in a mouse allergic asthma model, the development of Th2-dependent eosinophilic airway inflammation and airway hyperresponsiveness was revealed to be highly dependent on the protein expression levels of SHP-1. Thus, research efforts aimed at modifying SHP-1 expression and/or function may be helpful for establishing new approaches to the treatment of inflammatory diseases such as bronchial asthma.

\section{Acknowledgments}

The authors are grateful to Ralph T. Kubo for helpful comments and constructive criticism in the preparation of the manuscript. The authors thank K. Harigaya, M. Higashi, and H. Nakajima for comments on the histological analyses. This work was supported by grants from the Ministry of Education, Culture, Sports, Science and Technology (Japan) (Grants-in-Aid for Scientific Research, Priority Areas Research, nos. 
13218016 and 12051203; Scientific Research A, no. 13307011; Scientific Research B, no. 14370107; and Scientific Research C, no. 12670293; and Special Coordination Funds) and the Ministry of Health, Labor and Welfare (Japan), the Organization of Pharmaceutical Safety and Research (Japan) (Program for the Promotion of Fundamental Studies in Health Science), and by a Human Frontier Science Program Research Grant (RG00168/2000-M206).

1. Mosmann, T.R., Cherwinski, H., Bond, M.W., Giedlin, M.A., and Coffman, R.L. 1986. Two types of murine helper T cell clone. I. Definition according to profiles of lymphokine activities and secreted proteins. J. Immunol. 136:2348-2357.

2. Seder, R.A., and Paul, W.E. 1994. Acquisition of lymphokine-producing phenotype by CD4+ T cells. Annu. Rev. Immunol. 12:635-673.

3. Abbas, A.K., Murphy, K.M., and Sher, A. 1996. Functional diversity of helper T lymphocytes. Nature. 383:787-793.

4. O'Garra, A. 1998. Cytokines induce the development of functionally heterogeneous T helper cell subsets. Immunity. 8:275-283.

5. Reiner, S.L., and Seder, R.A. 1999. Dealing from the evolutionary pawnshop: how lymphocytes make decisions. Immunity. 11:1-10

6. Takeda, K., et al. 1996. Essential role of Stat6 in IL-4 signaling. Nature. 380:627-630.

7. Shimoda, K., et al. 1996. Lack of IL-4-induced Th2 response and IgE class switching in mice with disrupted Stat6 gene. Nature. 380:630-633.

8. Kaplan, M.H., Daniel, C., Schindler, U., and Grusby, M.J. 1998. Stat proteins control lymphocyte proliferation by regulating p27Kip1 expression. Mol. Cell. Biol. 18:1996-2003.

9. Yamashita, M., et al. 2000. T cell receptor-induced calcineurin activation regulates T helper type 2 cell development by modifying the interleukin 4 receptor signaling complex. J. Exp. Med. 191:1869-1879.

10. Yamashita, M., et al. 1999. T cell antigen receptor-mediated activation of the Ras/mitogen-activated protein kinase pathway controls interleukin 4 receptor function and type- 2 helper T cell differentiation. Proc. Natl. Acad. Sci. USA. 96:1024-1029.

11. Matthews, R.J., Bowne, D.B., Flores, E., and Thomas, M.L. 1992. Characterization of hematopoietic intracellular protein tyrosine phosphatases: description of a phosphatase containing an $\mathrm{SH} 2$ domain and another enriched in proline-, glutamic acid-, serine-, and threonine-rich sequences. Mol. Cell. Biol. 12:2396-2405.

12. Zhang, J., Somani, A.K., and Siminovitch, K.A. 2000. Roles of the SHP-1 tyrosine phosphatase in the negative regulation of cell signalling. Semin. Immunol. 12:361-378.

13. Neel, B.G. 1997. Role of phosphatases in lymphocyte activation. Curr. Opin. Immunol. 9:405-420.

14. Siminovitch, K.A., and Neel, B.G. 1998. Regulation of B cell signal transduction by $\mathrm{SH} 2$-containing protein-tyrosine phosphatases. Semin. Immunol. 10:329-347.

15. Townley, R., Shen, S.H., Banville, D., and Ramachandran, C. 1993. Inhibition of the activity of protein tyrosine phosphate $1 \mathrm{C}$ by its $\mathrm{SH} 2$ domains. Biochemistry. 32:13414-13418.

16. Pei, D., Wang, J., and Walsh, C.T. 1996. Differential functions of the two Src homology 2 domains in protein tyrosine phosphatase SH-PTP1. Proc. Natl. Acad. Sci. USA. 93:1141-1145.

17. Tsui, H.W., Siminovitch, K.A., de Souza, L., and Tsui, F.W. 1993. Motheaten and viable motheaten mice have mutations in the haematopoietic cell phosphatase gene. Nat. Genet. 4:124-129.

18. Shultz, L.D., et al. 1993. Mutations at the murine motheaten locus are within the hematopoietic cell protein-tyrosine phosphatase (Hcph) gene. Cell. 73:1445-1454.

19. Pani, G., Kozlowski, M., Cambier, J.C., Mills, G.B., and Siminovitch, K.A 1995. Identification of the tyrosine phosphatase PTP1C as a B cell antigen receptor-associated protein involved in the regulation of $\mathrm{B}$ cell signaling. J. Exp. Med. 181:2077-2084.

20. Wu, Y., Pani, G., Siminovitch, K., and Hozumi, N. 1995. Antigen receptor-triggered apoptosis in immature $B$ cell lines is associated with the binding of a 44-kDa phosphoprotein to the PTP1C tyrosine phosphatase. Eur. J. Immunol. 25:2279-2284.

21. Ono, M., et al. 1997. Deletion of SHIP or SHP-1 reveals two distinct pathways for inhibitory signaling. Cell. 90:293-301.

22. Doody, G.M., et al. 1995. A role in B cell activation for CD22 and the protein tyrosine phosphatase SHP. Science. 269:242-244.

23. Blasioli, J., Paust, S., and Thomas, M.L. 1999. Definition of the sites of interaction between the protein tyrosine phosphatase SHP-1 and CD22. J. Biol. Chem. 274:2303-2307.

24. Binstadt, B.A., et al. 1996. Sequential involvement of Lck and SHP-1 with MHC-recognizing receptors on NK cells inhibits FcR-initiated tyrosine kinase activation. Immunity. 5:629-638.

25. Burshtyn, D.N., et al. 1996. Recruitment of tyrosine phosphatase HCP by the killer cell inhibitor receptor. Immunity. 4:77-85.

26. Campbell, K.S., Dessing, M., Lopez-Botet, M., Cella, M., and Colonna, M. 1996. Tyrosine phosphorylation of a human killer inhibitory receptor recruits protein tyrosine phosphatase 1C. J. Exp. Med. 184:93-100.

27. Pani, G., Fischer, K.D., Mlinaric-Rascan, I., and Siminovitch, K.A. 1996. Signaling capacity of the $\mathrm{T}$ cell antigen receptor is negatively regulated by the PTP1C tyrosine phosphatase. J. Exp. Med. 184:839-852.

28. Lorenz, U., Ravichandran, K.S., Burakoff, S.J., and Neel, B.G. 1996. Lack of SHPTP1 results in src-family kinase hyperactivation and thymocyte hyperresponsiveness. Proc. Natl. Acad. Sci. USA. 93:9624-9629.

29. Plas, D.R., et al. 1996. Direct regulation of ZAP-70 by SHP-1 in T cell antigen receptor signaling. Science. 272:1173-1176.

30. Zhang, J., et al. 1999. Involvement of the SHP-1 tyrosine phosphatase in regulation of T cell selection. J. Immunol. 163:3012-3021.

31. Plas, D.R., et al. 1999. Cutting edge: the tyrosine phosphatase SHP-1 regulates thymocyte positive selection. J. Immunol. 162:5680-5684.

32. Johnson, K.G., LeRoy, F.G., Borysiewicz, L.K., and Matthews, R.J. 1999. TCR signaling thresholds regulating $\mathrm{T}$ cell development and activation are dependent upon SHP-1. J. Immunol. 162:3802-3813.

33. Carter, J.D., Neel, B.G., and Lorenz, U. 1999. The tyrosine phosphatase SHP-1 influences thymocyte selection by setting TCR signaling thresholds. Int. Immunol. 11:1999-2014.

34. Klingmuller, U., Lorenz, U., Cantley, L.C., Neel, B.G., and Lodish, H.F. 1995. Specific recruitment of SH-PTP1 to the erythropoietin receptor causes inactivation of JAK2 and termination of proliferative signals. Cell. 80:729-738.

35. Petricoin, E., 3rd, et al. 1996. Inhibition of alpha interferon but not gamma interferon signal transduction by phorbol esters is mediated by a tyrosine phosphatase. Mol. Cell. Biol. 16:1419-1424.

36. Migone, T.S., et al. 1998. Recruitment of SH2-containing protein tyrosine phosphatase SHP-1 to the interleukin 2 receptor; loss of SHP-1 expression in human T-lymphotropic virus type I-transformed T cells. Proc. Natl. Acad. Sci. USA. 95:3845-3850.

37. Yi, T., Mui, A.L., Krystal, G., and Ihle, J.N. 1993. Hematopoietic cell phosphatase associates with the interleukin-3 (IL-3) receptor $\beta$ chain and down-regulates IL-3-induced tyrosine phosphorylation and mitogenesis. Mol. Cell. Biol. 13:7577-7586.

38. Haque, S.J., Harbor, P., Tabrizi, M., Yi, T., and Williams, B.R. 1998. Protein-tyrosine phosphatase Shp-1 is a negative regulator of IL-4- and IL13-dependent signal transduction. J. Biol. Chem. 273:33893-33896.

39. McFadden, E.R., Jr., and Gilbert, I.A. 1992. Asthma. N. Engl. J. Med. 327:1928-1937.

40. Robinson, D.S., et al. 1992. Predominant TH2-like bronchoalveolar Tlymphocyte population in atopic asthma. N. Engl. J. Med. 326:298-304.

41. Lloyd, C.M., Gonzalo, J.A., Coyle, A.J., and Gutierrez-Ramos, J.C. 2001. Mouse models of allergic airway disease. Adv. Immunol. 77:263-295.

42. Wills-Karp, M. 1999. Immunologic basis of antigen-induced airway hyperresponsiveness. Annu. Rev. Immunol. 17:255-281.

43. Drazen, J.M., Arm, J.P., and Austen, K.F. 1996. Sorting out the cytokines of asthma. J. Exp. Med. 183:1-5.

44. Venkayya, R., et al. 2002. The Th2 lymphocyte products IL-4 and IL-13 rapidly induce airway hyperresponsiveness through direct effects on resident airway cells. Am. J. Respir. Cell Mol. Biol. 26:202-208.

45. Nakajima, H., et al. 1992. CD4+ T-lymphocytes and interleukin-5 mediate antigen-induced eosinophil infiltration into the mouse trachea. Am. Rev. Respir. Dis. 146:374-377.

46. Foster, P.S., Hogan, S.P., Ramsay, A.J., Matthaei, K.I., and Young, I.G. 1996. Interleukin 5 deficiency abolishes eosinophilia, airways hyperreactivity, and lung damage in a mouse asthma model. J. Exp. Med. 183:195-201.

47. Hamelmann, E., et al. 1999. Anti-interleukin 5 but not anti-IgE prevents airway inflammation and airway hyperresponsiveness. Am. J. Respir. Crit. Care Med. 160:934-941.

48. Kuperman, D., Schofield, B., Wills-Karp, M., and Grusby, M.J. 1998. Signal transducer and activator of transcription factor 6 (Stat6)-deficient mice are protected from antigen-induced airway hyperresponsiveness and mucus production. J. Exp. Med. 187:939-948.

49. Yang, L., et al. 1998. Essential role of nuclear factor $\kappa B$ in the induction of eosinophilia in allergic airway inflammation. J. Exp. Med. 188:1739-1750.

50. Zhang, D.H., et al. 1999. Inhibition of allergic inflammation in a murine model of asthma by expression of a dominant-negative mutant of GATA-3. Immunity. 11:473-482.

51. Finotto, S., et al. 2001. Treatment of allergic airway inflammation and hyperresponsiveness by antisense-induced local blockade of GATA-3 expression. J. Exp. Med. 193:1247-1260.

52. Kimura, M., et al. 2001. Regulation of Th2 cell differentiation by mel-18, a mammalian polycomb group gene. Immunity. 15:275-287.

53. Hansen, G., Berry, G., DeKruyff, R.H., and Umetsu, D.T. 1999. Allergenspecific Th1 cells fail to counterbalance Th2 cell-induced airway hyperre- 
activity but cause severe airway inflammation. J. Clin. Invest. 103:175-183.

54. Hamelmann, E., et al. 1997. Noninvasive measurement of airway responsiveness in allergic mice using barometric plethysmography. Am. J. Respir. Crit. Care Med. 156:766-775.

55. Mohrs, M., et al. 1999. Differences between IL-4- and IL-4 receptor alpha-deficient mice in chronic leishmaniasis reveal a protective role for IL-13 receptor signaling. J. Immunol. 162:7302-7308.

56. Huang, H., and Paul, W.E. 2000. Protein tyrosine phosphatase activity is required for IL-4 induction of IL-4 receptor $\alpha$-chain. J. Immunol. 164:1211-1215

57. Simons, K., and Ikonen, E. 1997. Functional rafts in cell membranes. Nature. 387:569-572.

58. Clements, J.L., Boerth, N.J., Lee, J.R., and Koretzky, G.A. 1999. Integration of $\mathrm{T}$ cell receptor-dependent signaling pathways by adapter proteins. Annu. Rev. Immunol. 17:89-108.

59. Chan, A.C., Desai, D.M., and Weiss, A. 1994. The role of protein tyrosine kinases and protein tyrosine phosphatases in $\mathrm{T}$ cell antigen receptor signal transduction. Annu. Rev. Immunol. 12:555-592.

60. Brockdorff, J., Williams, S., Couture, C., and Mustelin, T. 1999. Dephosphorylation of ZAP-70 and inhibition of T cell activation by activated SHP1. Eur. J. Immunol. 29:2539-2550.

61. Takeda, K., et al. 1997. Development of eosinophilic airway inflammation and airway hyperresponsiveness in mast cell-deficient mice. J. Exp. Med. 186:449-454.

62. Williams, C.M., and Galli, S.J. 2000. Mast cells can amplify airway reactivity and features of chronic inflammation in an asthma model in mice. J. Exp. Med. 192:455-462.

63. Kobayashi, T., et al. 2000. An essential role of mast cells in the development of airway hyperresponsiveness in a murine asthma model. J. Immunol. 164:3855-3861.

64. Wills-Karp, M., et al. 1998. Interleukin-13: central mediator of allergic asthma. Science. 282:2258-2261.

65. Grunig, G., et al. 1998. Requirement for IL-13 independently of IL-4 in experimental asthma. Science. 282:2261-2263.

66. Walter, D.M., et al. 2001. Critical role for IL-13 in the development of allergen-induced airway hyperreactivity. J. Immunol. 167:4668-4675.

67. Qu, C.K., Nguyen, S., Chen, J., and Feng, G.S. 2001. Requirement of Shp2 tyrosine phosphatase in lymphoid and hematopoietic cell development. Blood. 97:911-914.

68. Yasukawa, H., Sasaki, A., and Yoshimura, A. 2000. Negative regulation of cytokine signaling pathways. Annu. Rev. Immunol. 18:143-164.

69. Deng, C., et al. 2002. Expression of the tyrosine phosphatase SRC homology 2 domain-containing protein tyrosine phosphatase 1 determines $\mathrm{T}$ cell activation threshold and severity of experimental autoimmune encephalomyelitis. J. Immunol. 168:4511-4518.

70. Dabbagh, K., Dahl, M.E., Stepick-Biek, P., and Lewis, D.B. 2002. Toll-like receptor 4 is required for optimal development of Th2 immune responses: role of dendritic cells. J. Immunol. 168:4524-4530.

71. Ray, A., and Cohn, L. 1999. Th2 cells and GATA-3 in asthma: new insights into the regulation of airway inflammation. J. Clin. Invest. 104:985-993.

72. Barnes, P.J. 2001. Cytokine-directed therapies for asthma. J. Allergy Clin. Immunol. 108(Suppl. 2):S72-S76.

73. Shirakawa, T., Enomoto, T., Shimazu, S., and Hopkin, J.M. 1997. The inverse association between tuberculin responses and atopic disorder. Science. 275:77-79.

74. Kline, J.N., et al. 1998. Modulation of airway inflammation by CpG oligodeoxynucleotides in a murine model of asthma. J. Immunol. 160:2555-2559.

75. Shirota, H., Sano, K., Kikuchi, T., Tamura, G., and Shirato, K. 2000. Regulation of murine airway eosinophilia and Th2 cells by antigen-conjugated $\mathrm{CPG}$ oligodeoxynucleotides as a novel antigen-specific immunomodulator. J. Immunol. 164:5575-5582.

76. Laporte, J.C., et al. 2001. Direct effects of interleukin-13 on signaling pathways for physiological responses in cultured human airway smooth muscle cells. Am. J. Respir. Crit. Care Med. 164:141-148. 